\title{
Attitudes to bone health amongst educated women aged $25-45$ years
}

\author{
S. M. O'Donnell ${ }^{1}$, P. T. Danh ${ }^{2}$ and H. E. Theobald ${ }^{2}$ \\ ${ }^{1}$ School of Biomedical Sciences, University of Ulster, Coleraine BT52 1SA, UK and ${ }^{2}$ GlaxoSmithKline Nutritional \\ Healthcare R\&D, Slough SL1 3NW, UK
}

At age 50 years women are at greater risk of experiencing bone fracture than breast cancer or CVD ${ }^{(1)}$. However, whilst public health campaigns and media articles focus on the prevention of cancers and CVD, few focus on bone health.

An online survey (Classapps Selectsurvey.net; Classapps.com, Overland Park, KS, USA) to assess attitudes and beliefs towards Ca and bone health was conducted amongst female employees, aged 25-45 years at GlaxoSmithKline, UK. Thirty-three questions were asked, of which twenty-eight questions probed knowledge, beliefs and attitudes towards $\mathrm{Ca}$ and bone health. Questions consisted either of multiplechoice responses ( $n$ 20), ranking questions $(n 2)$, open-ended questions $(n 4)$ or questions where participants rated their extent of agreement with a series of statements $(n 2)$. A total of 266 individuals who had previously expressed an interest in conducting consumer insight research for the company were invited to participate in the study. A total of 134 subjects fulfilled the inclusion criteria and answered sufficient questions to be included in the analysis, giving a response rate of 50.4\%. Participants had a mean age of 35.1 (SE 0.46) years and were highly educated (37.3\% having attained a Bachelors degree or equivalent and 30.6\% a Masters degree or PhD).

Three banks of questions probed attitudes towards bone health. Of the 130 participants who answered questions specifically relating to attitudes towards bone health, thirteen $(10.0 \%)$ stated that they were concerned and sixty-eight $(52.3 \%)$ were somewhat concerned about bone health and disease. Asked why participants were not concerned or only somewhat concerned about bone health, the majority responded that their current diets and lifestyles would help lower their risk of bone disease (42\% reported following a healthy lifestyle that would lower risk; $18 \%$ reported to consume a high-Ca diet and $12 \%$ reported that they participated in weight-bearing exercise to reduce risk). Additionally, participants were asked to agree or disagree, to various extents, with a number of statements relating to their attitudes to bone health. The Table shows the extent of agreement (number and percentage) with each statement.

\begin{tabular}{|c|c|c|c|c|c|c|c|c|c|c|c|}
\hline \multirow[b]{2}{*}{ Questions } & \multicolumn{2}{|c|}{ Strongly agree } & \multicolumn{2}{|c|}{ Agree } & \multicolumn{2}{|c|}{ Neutral } & \multicolumn{2}{|c|}{ Disagree } & \multicolumn{2}{|c|}{ Strongly Disagree } & \multirow[b]{2}{*}{ Total $n$} \\
\hline & $n$ & $\%$ & $n$ & $\%$ & $n$ & $\%$ & $n$ & $\%$ & $n$ & $\%$ & \\
\hline Healthy bones are really important to me & 47 & 36.2 & 72 & 55.4 & 10 & 7.7 & 1 & 0.8 & 0 & 0 & 130 \\
\hline I associate bone disease with the elderly & 13 & 10.0 & 70 & 53.8 & 16 & 12.3 & 22 & 16.9 & 9 & 6.9 & 130 \\
\hline Bone health is not really relevant to me right now & 0 & 0 & 15 & 11.5 & 27 & 20.7 & 64 & 49.2 & 24 & 18.5 & 130 \\
\hline $\begin{array}{l}\text { I am willing to change my diet \& lifestyle to help } \\
\text { maintain positive bone health }\end{array}$ & 19 & 14.6 & 91 & 70.0 & 19 & 14.6 & & 0.8 & 0 & 0 & 130 \\
\hline $\begin{array}{l}\text { Maintaining bone health isn't as important to me as } \\
\text { prevention of cancer \& heart disease }\end{array}$ & 10 & 7.7 & 42 & 32.3 & 33 & 25.4 & 38 & 29.2 & 7 & 5.4 & 130 \\
\hline
\end{tabular}

The findings from the survey suggest that women aged 25-45 years are as concerned about their future bone health as they are about cancer and heart disease and are willing to change both their diets and lifestyles to preserve bone health, suggesting that public health awareness campaigns promoting bone health may be well received amongst this group of women. These findings contradict a previous study that reported that despite good knowledge relating to bone health and disease, many women are unconcerned about bone health and are unwilling to change their lifestyles to promote bone health ${ }^{(2)}$.

1. Kanis JA (1994) Osteoporos Int 4, 368-381.

2. Anderson JE, Auld GW \& Schiltz CM (1996) J Wellness Perspect 12, 63-69. 